\title{
Ethics and social accountability - two sides of the same coin integrating social accountability in medical education
}

\author{
Kausar S. Khan \& Sohail Amir Ali Bawani \\ Department of Community Health Sciences, Aga Khan University, Pakistan
}

\section{Context \& reason for the idea}

Health care providers, whether doctors or nurses are duty bearers and responsible for addressing the health needs of people. Medical schools are responsible for building required competencies, and provide cutting edge training to the doctors, equipping them with the knowledge, skills and related competencies to treat the patients that come to them. However, medical schools while imparting medical training assume that the same curriculum will also build social accountability of their profession.

In May-June 2013, AKU organized its 18th Post Graduate Medical Education Conference. The theme of the conference was 'Social Accountability in Health Profession Education'. There was opportunity for offering post conference workshops. The Bioethics Group (BG) at the Aga Khan University, decided to offer a workshop as it believes that ethics and social accountability are two sides of the same coin. The workshop was titled 'Integrating Social Accountability in Medical Education'

\section{Methods}

Constructivist approach to teaching and learning was used to explore the relationship between social accountability and medical education (Duffy \& Cunningham, 1996). Collective learning of participants was encouraged during the workshop, as opposed to individual learning. Individual work, sharing of individual work in the group, and seeking clarifications were the key learning methods used in the workshop. There were four steps participants were taken through to the session. First, participants were asked to brainstorm what they understand by social accountability. Since, it was a post conference workshop; the facilitators assumed that the participants will have some understanding of the concept. Their responses were documented and were displayed. Second, participants were asked to pick their favorite key concepts and then were required to categorize them. This helped participants to identify contents of Social Accountability in Medical Education. Third, two curricula developed at AKU for undergraduate medical education and for the Master in Bioethics, were presented to the participants. After a review of the two curricula participants were asked to propose the content for teaching social accountability to the post graduate medical trainees of AKU Mechanism for taking forward the initial thinking on integrating social accountability in post graduate medical education, were also discussed. The workshop process and its conclusions were to be distributed to the participants after the workshop so that they could share their thinking with their colleagues, and specially those who are members of the curriculum committee.

\section{Evaluation}

Collective feedback was taken at the end of the workshop. Each participant, including facilitators involved, was requested to freely say what they learnt through the session and also share any concern or criticism. Many participants shared that the social construction of fear that becomes a hurdle to being socially accountable. However, they were encouraged and excited about taking the social accountability agenda forward. Formal evaluation showed that $60 \%$ rated the workshop as excellent (highest score on a scale of one five); $20 \%$ as good (second highest score) and $20 \%$ found it to be average (third highest).

\section{Reference}

1. Duffy, T.M., \& Cunningham, D.J. (1996). Constructivism: implications for the design and delivery of instruction. In D. H. Jonassen, (Ed.). Handbook of Research for Educational Communications and Technology, New York: Simon and Schuster, pp. 170-198.

(C) Medical Education Department, School of Medical Sciences, Universiti Sains Malaysia. All rights reserved.

CORRESPONDING AUTHOR: Sohail Amir Ali Bawani, Department of Community, Health Sciences, Aga Khan University, Stadium Road, P.O. Box 3500, Karachi, 74800, Pakistan. Email: sohail.bawani@aku.edu 